\title{
Palm Kernel Shell Activated Carbon as an Inorganic Framework for Shape-Stabilized Phase Change Material
}

\author{
Ahmad Fariz Nicholas ${ }^{1}$, Mohd Zobir Hussein ${ }^{1, *(D)}$, Zulkarnain Zainal ${ }^{1}$ (D) \\ and Tumirah Khadiran ${ }^{2}$ \\ 1 Materials Synthesis and Characterization Laboratory, Institute of Advanced Technology (ITMA), \\ Universiti Putra Malaysia, 43400 Serdang, Selangor, Malaysia; ahmadfariznicholas@yahoo.com (A.F.N.); \\ zulkar@upm.edu.my (Z.Z.) \\ 2 Forest Product Division, Forest Research Institute Malaysia (FIRM), 52109 Kepong, Selangor, Malaysia; \\ tumirah@frim.gov.com \\ * Correspondence: mzobir@upm.edu.my; Tel.: +60-3-89468092
}

Received: 26 July 2018; Accepted: 30 August 2018; Published: 5 September 2018

\begin{abstract}
The preparation of activated carbon using palm kernel shells as the precursor (PKSAC) was successfully accomplished after the parametric optimization of the carbonization temperature, carbonization holding time, and the ratio of the activator $\left(\mathrm{H}_{3} \mathrm{PO}_{4}\right)$ to the precursor. Optimization at $500{ }^{\circ} \mathrm{C}$ for $2 \mathrm{~h}$ of carbonization with $20 \% \mathrm{H}_{3} \mathrm{PO}_{4}$ resulted in the highest surface area of the activated carbon (C20) of $1169 \mathrm{~m}^{2} \mathrm{~g}^{-1}$ and, with an average pore size of $27 \AA$. Subsequently, the preparation of shape-stabilized phase change material (SSPCM-C20) was done by the encapsulation of n-octadecane into the pores of the PKSAC, C20. The field emission scanning electron microscope images and the nitrogen gas adsorption-desorption isotherms show that n-octadecane was successfully encapsulated into the pores of C20. The resulting SSPCM-C20 nano-composite shows good thermal reliability which is chemically and thermally stable and can stand up to 500 melting and freezing cycles. This research work provided a new strategy for the preparation of SSPCM material for thermal energy storage application generated from oil palm waste.
\end{abstract}

Keywords: activated carbon; palm kernel shell; phase change material; thermal energy storage; paraffin

\section{Introduction}

Malaysia, Indonesia, Thailand, African countries like Nigeria, Cameroon and several Southern provinces of China are among the top producers of palm oil in the world [1]. As the leading producer and supplier of the oil palm, Malaysia keeps on increasing the production of palm oil by developing oil palm plantations beginning with only 54,000 hectares in the early $1960 \mathrm{~s}$, expected to increase to 5.1 million hectares by 2020 [2]. The oil palm industries in Malaysia are producing about $90 \times 10^{6}$ tons of lignocellulosic biomass each year, of which empty fruit bunch (EFB), oil palm trunk (OPT) and oil palm fronds (OPF) are about $40 \times 10^{6}$ tons [3]. It is an opportunity for oil palm industries to use these wastes to turn them into valuable products instead of discarding them by open burning [4] which resulted in bad consequences for the environment. The increasing number of waste material from industrial development contributed to the deterioration of the earth through ozone depletion. Oil palm solid waste (OPSW) like palm kernel shell is a good candidate for the production of activated carbon as it contains a highly developed porosity and surface area because of its high carbon content and relatively low price [5].

Palm kernel shell is a sustainable source of materials included in the economic sector which is responsible for the breakdown of global greenhouse gas emissions and climate change. 
Many industries, academics, and governmental agencies are now focusing on the green chemistry and engineering technologies to minimize the negative impacts towards the environment [6]. The manufacturing processes are now restructured by the application of green solvents and reagents, energy conservations, waste minimization, and utilization of natural resources.

Consisting of about $87 \%$ to $97 \%$ of carbon and other elements such as hydrogen, oxygen, sulfur and nitrogen, activated carbon has a very high adsorption capability by having the highest volume of adsorbing porosity [7]. Activated carbon with highly developed porosity, has a large surface area, a high micropore volume $\left(\mathrm{V}_{\mathrm{mic}}\right)$, a favourable pore size distribution, and thermal stability [8]. The surface area of activated carbon is usually more than $1000 \mathrm{~m}^{2} / \mathrm{g}$. Activated carbon has a random imperfect structure which consists of a broad range of pore sizes-micro, meso, and macro-that makes activated carbon different from graphite [7] or other carbon materials. The surface of the activated carbon can be used to accumulate contaminants as it contains the protonated $\left(\mathrm{C}-\mathrm{OH}_{2}{ }^{+}\right)$, neutral $(\mathrm{COH})$, or ionized $\left(\mathrm{CO}^{-}\right)$groups [9].

Activated carbon can be prepared using three main methods: chemical, physical and physicochemical activations. Researchers used the chemical method at the beginning of the activated carbon production era, but recently the physical and physicochemical methods are more preferred for the production of activated carbon, especially from oil palm solid waste. Chemical activation is the most widely used for the production as it provides a superior quality, high surface area, high porosity, and higher carbon yield [10]. Activating agents such as $\mathrm{KOH}, \mathrm{ZnCl}_{2}, \mathrm{~K}_{2} \mathrm{CO}_{3}$, and $\mathrm{H}_{3} \mathrm{PO}_{4}$ are usually used as they help to develop the pore structure of the activated carbon [11]. The most popular chemical activating agents that were used for the activation of activated carbon are $\mathrm{ZnCl}_{2}$ and $\mathrm{H}_{3} \mathrm{PO}_{4}$. It inhibits the tar formation and widens the porous structure of the activated carbon by increasing the carbon yield. The chemical activation by $\mathrm{KOH}$ and $\mathrm{K}_{2} \mathrm{CO}_{3}$ show different mechanism as the reaction with carbon causes carbon gasification and the formation of hydrogen, which will not contribute to the increase in carbon yield [12].

Controlling the activation process by chemical treatment will enable one to enhance and provide higher specific surface properties to the resulting activated carbon [13]. In chemical activation, an acidic or basic solution is used as the activating agent to produce a higher surface area and porosity [8]. There are several activating agents which are usually used in treating the OPSW such as $\mathrm{H}_{3} \mathrm{PO}_{4}$, $\mathrm{K}_{2} \mathrm{CO}_{3}, \mathrm{KOH}, \mathrm{ZnCl}_{2}$, and $\mathrm{H}_{2} \mathrm{SO}_{4}$. The synthesis method will determine the resulting physicochemical characteristics of the activated carbon as it depends on the activating agent, the amount of the precursor, the condition of the activation process, and the raw materials used [7]. Proper chemical management is needed to discharge the activating agent after sample treatment in order to prevent pollutions. There are several methods that can be adapted to dispose of this highly polluting effluent, such as the treatment system based on membrane technology [14], in situ solvent and reagent recycle by Nanofiltration [15], or by solvent recycle with imperfect membranes by the separation method [16].

Thermal energy storage is an energy storage device that functions to develop a new energy source which is very important to help in conserving energy which, in turn, reduces the negative impact towards the polluted environment [17]. Phase change material (PCM) is the medium for latent heat thermal energy storage in which the energy stored will be used based on energy supply and demand when there is a change of phase caused by the freezing or melting processes [18]. Solid-liquid PCM such as n-octadecane is very useful as it can store a large quantity of energy with small changes of volume. In addition, it also possesses desirable properties such as a high latent heat, chemical inertness, no phase segregation, and it is commercially available [19]. In the preparation of the SSPCM nano-composite, the PCM was encapsulated into the activated carbon pores or inorganic frameworks to prevent any leakage during the solid-liquid phase transition.

In this work, the preparation of activated carbon from palm kernel shell will be studied and the resulting activated carbon will be subsequently used as inorganic frameworks for the preparation of shape-stabilized phase change material (SSPCM) for the thermal energy storage (TES) application. Parametric optimization for the preparation of activated carbon was done in order to obtain the highest 
graphitic content with the highest surface area and porosity. Three different parameters, namely, activation temperature, activation holding time, and concentration of $\mathrm{H}_{3} \mathrm{PO}_{4}$ were optimized.

\section{Materials and Methods}

\subsection{List of Materials}

Palm kernel shell (PKS), deionized water, orthophosphoric acid (85\%) (SystermChemAR, Shah Alam, Malaysia), ethyl alcohol (99.7\%) (R\&M Chemicals, Semenyih, Malaysia), and octadecane (99\%) (Aldrich Chemistry, St. Louis, MO, USA) were used in this work.

\subsection{Pre-Treatment of Palm Kernel Shell}

The palm kernel shell (PKS) samples were collected from the Seri Ulu Langat Palm Oil Mill, Dengkil, Selangor, to be used as the precursor for the activated carbon production. The PKS was cleaned using water, followed by de-ionized water. The sample was crushed into powder using a stable arm grinder before it was treated with $\mathrm{H}_{3} \mathrm{PO}_{4}$. About $20 \mathrm{~g}$ of the precursor was weighted and treated with $100 \mathrm{~mL}$ of freshly prepared $\mathrm{H}_{3} \mathrm{PO}_{4}$ at various concentrations of $\mathrm{H}_{3} \mathrm{PO}_{4}: 0 \%, 5 \%, 10 \%, 20 \%$, $30 \%$, and $40 \%(v / v)$ using $85 \% \mathrm{H}_{3} \mathrm{PO}_{4}$. Treatment was done in a conical flask with the ratio of $1: 5$ of $20 \mathrm{~g}$ of PKS and $100 \mathrm{~mL}$ of freshly prepared $\mathrm{H}_{3} \mathrm{PO}_{4}$. After $24 \mathrm{~h}$ of treatment, the liquid was filtered off using a filter paper and the sample was dried in an oven at $70^{\circ} \mathrm{C}$ for $24 \mathrm{~h}$ before it was used as the precursor for AC preparation.

\subsection{Sample Activation}

An electrical tubular furnace was used in this one step activation with a constant flow rate of nitrogen gas at $150 \mathrm{~cm}^{3} \mathrm{~min}^{-1}$. The sample was activated in three different conditions based on the parameters to be optimized and this will be described in the following section.

\subsubsection{Carbonization Temperature}

The PKS samples of about $5 \mathrm{~g}$ were carbonized using a tubular furnace under a nitrogen gas environment. The sample treated with $20 \% \mathrm{H}_{3} \mathrm{PO}_{4}$ was chosen to study the effect of the carbonization temperature on the physicochemical properties of the activated carbons. The sample was carbonized at different temperatures: $500^{\circ} \mathrm{C}, 600^{\circ} \mathrm{C}, 700^{\circ} \mathrm{C}, 800^{\circ} \mathrm{C}$, and $900^{\circ} \mathrm{C}$ for $2 \mathrm{~h}$ with a holding time at a $10^{\circ} \mathrm{C}$ $\min ^{-1}$ heating rate. The resulting PKSACs prepared were crushed using a mortar and pestle before they were cleaned. The cleaned samples were oven-dried at $110{ }^{\circ} \mathrm{C}$ for $24 \mathrm{~h}$ to remove any remaining internal moisture. The samples were weighted and recorded again before they were kept in vials and labelled as T500, T600, T700, T800, and T900 for the sample prepared at carbonization temperatures of $500{ }^{\circ} \mathrm{C}, 600{ }^{\circ} \mathrm{C}, 700{ }^{\circ} \mathrm{C}, 800{ }^{\circ} \mathrm{C}$, and $900{ }^{\circ} \mathrm{C}$, respectively, for further used and various analyses.

\subsubsection{Carbonization Holding Time}

For this experiment, the sample that was treated with $20 \%$ of $\mathrm{H}_{3} \mathrm{PO}_{4}$ was subsequently chosen and carbonized at $500{ }^{\circ} \mathrm{C}$ at different holding times: $1 \mathrm{~h}, 2 \mathrm{~h}, 3 \mathrm{~h}, 4 \mathrm{~h}$, and $5 \mathrm{~h}$ at a $10^{\circ} \mathrm{C} \mathrm{min}{ }^{-1}$ heating rate. The as-produced activated carbons were crushed using a mortar and pestle before they were further cleaned. The cleaned samples were oven dried at $110{ }^{\circ} \mathrm{C}$ for $24 \mathrm{~h}$ to remove any internal moisture left during the preparation. The samples were then weighted and recorded again before they were kept into vials and labelled as H1, H2, H3, H4, and H5 for holding times of $1 \mathrm{~h}, 2 \mathrm{~h}, 3 \mathrm{~h}, 4 \mathrm{~h}$, and $5 \mathrm{~h}$, respectively, for further used and various analyses.

\subsubsection{Concentration of the Activating Agent, $\mathrm{H}_{3} \mathrm{PO}_{4}$}

Each treated sample that was prepared at different concentrations of $\mathrm{H}_{3} \mathrm{PO}_{4}$ was carbonized at $500{ }^{\circ} \mathrm{C}$ for $2 \mathrm{~h}$ of a holding time and at a $10^{\circ} \mathrm{C} \mathrm{min}{ }^{-1}$ heating rate. The resulting PKSACs were crushed using a mortar and pestle before it was cleaned. The cleaned samples were then oven-dried at $110^{\circ} \mathrm{C}$ 
for $24 \mathrm{~h}$ to remove any remaining internal moisture. The samples were then weighted and recorded again before they were kept into vials and labelled as C0, C5, C10, C20, C30 and C40 for treatment with $\mathrm{H}_{3} \mathrm{PO}_{4}$ at $0 \%, 5 \%, 10 \%, 20 \%, 30 \%$, and $40 \%$, respectively for further used and various analyses.

\subsection{Preparation of Shape-Stabilized Phase Change Materials}

A shape-stabilized phase change material (SSPCM) nano-composite was prepared by a simple impregnation method. About $30 \mathrm{~mL}$ of absolute ethanol was used to dissolve melted n-octadecane by heating above the melting temperature of n-octadecane above $28-30^{\circ} \mathrm{C}$. The prepared PKSAC, C20 was added into the n-octadecane solution and the solution was then stirred at $600 \mathrm{rpm}$ for $4 \mathrm{~h}$. The mixture was oven-dried at $80{ }^{\circ} \mathrm{C}$ for $48 \mathrm{~h}$ or until all the excess ethanol was evaporated. The SSPCM-C20 prepared was stored in a sample bottle for further used and characterization.

\subsection{Characterization Method}

The chemical characterization of PKSAC was carried out using the Raman spectroscopic method with a WiTec Raman spectrometer (WiTec, Ulm, Germany) using a $514 \mathrm{~nm}$ laser. The intensity ratio between the D-line $\left(\sim 1350 \mathrm{~cm}^{-1}\right)$ and the G-line $\left(\sim 1597 \mathrm{~cm}^{-1}\right)$ of the Raman spectra was used to evaluate the graphitic character of the PKSAC. In this study, characterizations were done for all the PKSACs prepared from the three different parameters: carbonization temperature, carbonization holding time, and concentration of the activating agent.

The surface area and porosity of PKSAC and SSPCM nano-composites were determined using the BET nitrogen gas adsorption-desorption method at $77 \mathrm{~K}$ using a Micromeratics Tristar II plus (Micromeratics, Norcross, GA, USA). The method was also conducted to identify whether the PCM, n-octadecane, can be impregnated into the newly prepared PKSAC pores or only adsorbed on the surface. The samples were degassed at $290{ }^{\circ} \mathrm{C}$ for $9 \mathrm{~h}$ under vacuum before the measurements and the specific surface area and pore size distribution of the samples was determined using the Brunauer-Emmet-Teller (BET) and BJH (Barret-Joyner-Halenda) Equations, respectively.

The chemical properties of the PKSAC and SSPCM nano-composites were carried out using the fourier-transform infrared spectroscopy (FTIR) on a Perkin Elmer BX FTIR spectrophotometer (Waltham, MA, USA) with the KBr method at room temperature. The absorbance was recorded from $400-4000 \mathrm{~cm}^{-1}$.

The powder X-ray diffraction (PXRD) patterns of PKSAC, n-octadecane, and SSPCM were obtained using a Shimadzu XRD-6000 PXRD (Kyoto, Japan) at room temperature with a scanning range of $10-35^{\circ}(2 \theta)$ and a scanning rate of $4^{\circ} \mathrm{min}^{-1}$ for all samples.

TGA/DTG thermal analyses were obtained using a Q500 V20.13 Build 39 (TA Instruments, Lukens Drive, New Castle, DE, USA) to investigate the thermal stability of the PKSAC, n-octadecane and SSPCM. The experiment was conducted using $10 \mathrm{mg}$ of samples and heated under the nitrogen atmosphere at a $5^{\circ} \mathrm{C} \mathrm{min}^{-1}$ heating rate from room temperature to $1000{ }^{\circ} \mathrm{C}$.

The thermal storage properties, such as the melting temperature, freezing temperature and enthalpy (latent heat) of the pure n-octadecane and SSPCM nano-composite were measured by a differential scanning calorimeter (DSC), 822e, Mettler Toledo equipped with a refrigerated cooling system. About $6 \pm 1 \mathrm{mg}$ of sample was weighed into an aluminium pan. Under a constant flow of nitrogen atmosphere with the flow rate of $60 \mathrm{~mL} / \mathrm{min}$, the measurements were performed at -20 to $70{ }^{\circ} \mathrm{C}$ for the heating cycle stage and 70 to $-20{ }^{\circ} \mathrm{C}$ for the cooling cycle stage. The encapsulation efficiency of n-octadecane in the nano-composite $s$ was calculated based on the enthalpy of pure n-octadecane using the following equation:

$$
\text { PCM content in nano }- \text { composite }(\text { wt } \%)=\left(\Delta \mathrm{H}_{\mathrm{m}} / \Delta \mathrm{H}_{\mathrm{PCM}}\right) \times 100
$$

where $\Delta \mathrm{H}_{\mathrm{m}}$ is the enthalpy of melting of the SSPCM nano-composite $\left(\mathrm{Jg}^{-1}\right)$ and $\Delta \mathrm{H}_{\mathrm{PCM}}$ is the enthalpy of melting for the pure n-octadecane $\left(\mathrm{Jg}^{-1}\right)$. 
The external surface morphology and microstructure of the PKS, PKSAC and SSPCM nano-composites were obtained using a Nova Nanosem 230 field emission scanning electron microscope (FESEM). The dried samples were dispersed on a conductive carbon adhesive tape surface that was attached to a FESEM stub and then gold-coated prior to the analysis.

To measure the chemical and thermal stability of the SSPCM nano-composite $\mathrm{s}$ to be used as a TES material, a thermal cycling test was conducted. This test is very important in determining a material's service lifetime. The test was performed at a relative humidity of $70 \%$ which was maintained constant using a climatic chamber (Weiss Umwelt Technik, UK) equipped with a K-type thermocouple in the middle [20]. About $5 \mathrm{~g}$ of the dried SSPCM nano-composite was placed in contact with the thermocouple in a chamber. The accuracy of the temperature measurement was $0.1{ }^{\circ} \mathrm{C}$. The nano-composite was subjected to 1000 thermal cycles at temperatures below and above the melting point of n-octadecane. Sampling was performed at 100, 300, 500, 700, and 1000 cycles. Changes in the samples' thermal properties and chemical stability after the thermal cycling test were determined using the DSC and FTIR technique, respectively.

The leakage study was performed by keeping the SSPCM nano-composite inside an oven at $80 \pm 5^{\circ} \mathrm{C}$ for 3 days $(72 \mathrm{~h}$ ). Before that, about $1 \mathrm{~g}$ of the nano-composite was weighed on a filter paper and exposed to $30^{\circ} \mathrm{C}$ for $8 \mathrm{~h}$ to study the ability of the $\mathrm{C} 20$ to hold n-octadecane during the melting phase. Then the samples were directly placed into an oven at $80 \pm 5^{\circ} \mathrm{C}$ for 3 days. The weight and the latent heat of the sample after the exposure period were recorded.

\section{Results and Discussion}

\subsection{Raman Spectroscopy}

The PKSAC samples were analyzed using the Raman spectroscopy to identify the graphitic character of the samples. The Raman spectra of all the PKSAC samples show two sharp peaks; a D band at around $1350 \mathrm{~cm}^{-1}$ and a G band at around $1597 \mathrm{~cm}^{-1}$ (Refer Figure S1: Raman spectra of PKSAC). The $\mathrm{G}$ band indicates the presence of a sp ${ }^{2}$ carbon network graphite-like structure which composed of either $\mathrm{C}=\mathrm{C}$ chains or aromatic ring structures. The $\mathrm{D}$ band in the Raman spectrum is due to the disordered graphite structure which refers to defects of the graphitic characteristics that also exists in all the PKSAC samples.

Figure 1a presents the plot of $\mathrm{I}_{\mathrm{G}} / \mathrm{I}_{\mathrm{D}}$ versus temperature $\left({ }^{\circ} \mathrm{C}\right)$ which shows that the graphitic character in the resulting PKSAC sample decreased almost linearly with the increased of the activation temperature. The highest graphitic content for the carbonization temperature is $500{ }^{\circ} \mathrm{C}$ with an $\mathrm{I}_{\mathrm{G}} / \mathrm{I}_{\mathrm{D}}$ value of 1.166 followed by $600{ }^{\circ} \mathrm{C}(1.106), 700{ }^{\circ} \mathrm{C}(1.034), 800{ }^{\circ} \mathrm{C}(0.963)$ and the lowest temperature of $900{ }^{\circ} \mathrm{C}(0.933)$. The graphitic value was found to decrease as the carbonization temperature increased and this is due to the reduction of amorphous carbon and the increase of the disorder aromatic carbon during the carbonization process [21].

Figure $1 \mathrm{~b}$ presents the plot of $\mathrm{I}_{\mathrm{G}} / \mathrm{I}_{\mathrm{D}}$ against the holding time $(\mathrm{h})$, which shows that no specific trend was observed between the graphitic characters in the PKSAC samples to the holding time. The highest value was obtained at 0.842 for the $\mathrm{H} 2$ sample followed by H4 (0.822), H5 (0.809), H1 (0.787), and H3 (0.754), the lowest. From the result, it is clear that the best holding time for the preparation of PKSAC with a high graphitic character is $2 \mathrm{~h}$.

Figure $1 \mathrm{c}$ shows a plot of the $\mathrm{I}_{\mathrm{G}} / \mathrm{I}_{\mathrm{D}}$ value of PKSAC against a concentration of $\mathrm{H}_{3} \mathrm{PO}_{4}(\% w / w)$ used for the activating agent for the PKSAC, indicating different graphitic contents of different samples of PKSAC. The highest graphitic character was observed for the sample prepared without any $\mathrm{H}_{3} \mathrm{PO}_{4}$ treatment, C0 (untreated sample) with a value of 1.5, followed by C5 (1.364), C10 (1.309), C20 (1.305), C30 (1.272), and C40 with the value of 1.074. Generally, it shows that the graphitic content of the PKSAC is indirectly proportional to the concentration of $\mathrm{H}_{3} \mathrm{PO}_{4}$. The higher the concentration, the lower the graphitic content in the resulting PKSAC and the weaker the physical structure of the sample. 


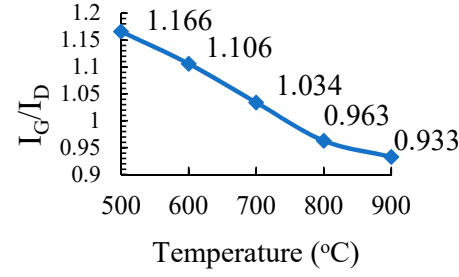

(a)

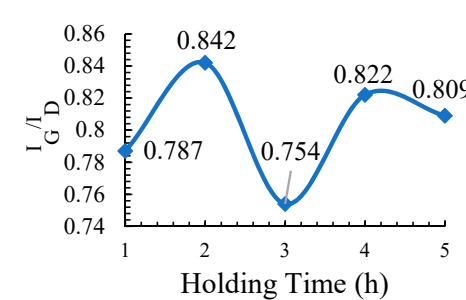

(b)

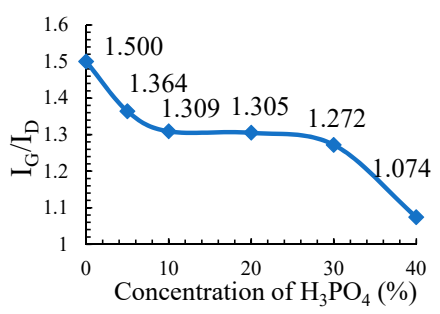

(c)

Figure 1. The plot of the $I_{G} / I_{D}$ against (a) carbonization temperature, (b) holding time, and (c) concentration of $\mathrm{H}_{3} \mathrm{PO}_{4}$ of the activated carbons.

\subsection{Surface Area and Porosity}

\subsubsection{Activated Carbon Framework}

The nitrogen adsorption-desorption isotherms of the three different parameters-carbonization temperature, holding time, and concentration of the activator-are shown in Figure $2 \mathrm{a}-\mathrm{c}$, respectively (Refer Figure S2: Adsorption-desorption isotherms). This study was carried out in order to get the highest surface area of the activated carbon for each of the parameters studied and finally identify the optimum temperature, activation holding time, and the concentration of $\mathrm{H}_{3} \mathrm{PO}_{4}$ treatment, in the preparation of the highest specific surface area of the activated carbon. All the samples are dominated by the Type 1 isotherm (according to the IUPAC classification) for all the parameters used in this study. The isotherm indicates that the AC is dominated by microporous-rich texture mixed with some of the mesopores with the highest BET specific surface area of $1168 \mathrm{~m}^{2} \mathrm{~g}^{-1}$ for the sample treated with $20 \%$ $\mathrm{H}_{3} \mathrm{PO}_{4}(\mathrm{C} 20)$.

Figure 2a shows the BET surface area of AC that was activated at $500{ }^{\circ} \mathrm{C}$, which shows the highest value. The surface area of the ACs decreased from $770 \mathrm{~m}^{2} \mathrm{~g}^{-1}$ to $464 \mathrm{~m}^{2} \mathrm{~g}^{-1}$ and $237 \mathrm{~m}^{2} \mathrm{~g}^{-1}$ when it was carbonized at 600 and $700{ }^{\circ} \mathrm{C}$. At 800 and $900{ }^{\circ} \mathrm{C}$, the surface area increased to $572 \mathrm{~m}^{2} \mathrm{~g}^{-1}$ and $679 \mathrm{~m}^{2} \mathrm{~g}^{-1}$, respectively. This shows that $500{ }^{\circ} \mathrm{C}$ was the best temperature to prepare the highest surface area of the AC. This relatively low temperature of carbonization is also good to reduce the use of energy which will reduce the cost of manufacturing.

Similar to the carbonization holding time as shown in Figure $2 b$, a carbonization holding time less or more than $2 \mathrm{~h}$ results in a lower BET surface area value. It shows that a $1 \mathrm{~h}$ holding time is not enough time to manufacture more pores in the $A C$ and when the samples were treated for more than $2 \mathrm{~h}$, the BET surface area and porosity value reduced with the increasing holding time. The sample was overtreated, which destroyed the pore formation of the AC. The overtreated samples extend the size of the pores from micro- to meso- and macro-pores sizes, which reduced the surface area and porosity of the AC. In other words, the porous structure development does not reach its optimum treatment when the $\mathrm{H}_{3} \mathrm{PO}_{4}$ concentration and activation holding time are lower or higher than the values of $20 \% \mathrm{H}_{3} \mathrm{PO}_{4}$ and a $2 \mathrm{~h}$ holding time.

The same result is shown with the concentration of the $\mathrm{H}_{3} \mathrm{PO}_{4}$ parameter (Figure 2c) in which the BET surface area of the AC treated with $20 \% \mathrm{H}_{3} \mathrm{PO}_{4}$ resulted in the highest surface area and this was subsequently used as the frameworks for the encapsulation of the PCM, n-octadecane, for the formation of a shape-stabilised PCM (SSPCM). 


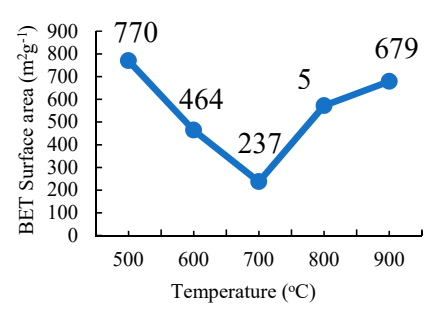

(a)

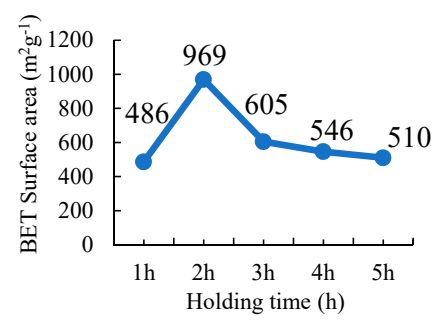

(b)

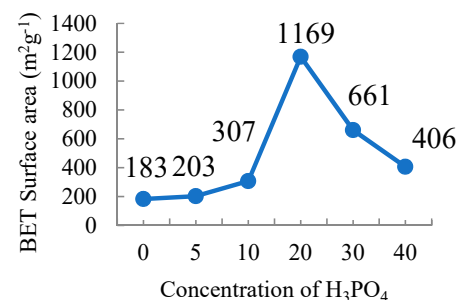

(c)

Figure 2. The plot of the Brunauer-Emmett-Teller surface area against (a) the carbonization temperature,(b) holding time, and (c) the amount of $\mathrm{H}_{3} \mathrm{PO}_{4}$ used as the chemical activator for the preparation of Palm kernel shell activated carbon.

Based on the parametric optimization for the preparation of PKSAC to be used as a framework for $\mathrm{PCM}$, it was found that activation at $500{ }^{\circ} \mathrm{C}$, with a $2 \mathrm{~h}$ activation holding time with $\mathrm{H}_{3} \mathrm{PO}_{4}$ of $20 \%$ treatment resulted in the highest surface area and welldeveloped porosity.

\subsubsection{Shape-Stabilized Phase Change Material}

The preparation of SSPCM-C20 was done by the impregnation of n-octadecane into the pores of activated carbon, C20. The BET surface area and porosity analysis for SSPCM-C20 was conducted to identify the surface properties changes before and after the encapsulation process. The SSPCM-C20 nano-composite was degassed at $290^{\circ} \mathrm{C}$ for $9 \mathrm{~h}$ under a vacuum before the specific surface area and pore size distribution by using the Brunauer-Emmet-Teller (BET) and BJH (Barret-Joyner-Halenda) equations were measured. The result shows that the adsorption-desorption isotherms transformed from the Type I in the AC-20 to the Type III in the SSPCM-C20 as shown in Figure 3a, indicating that the nano-composite is of a nonporous material. This material is parallel with almost no pore size distribution that can be clearly observed for SSPCM-C20 compared to C20 as shown in Figure 3b. The BET surface area, total pore volume, and pore diameter of the former are $2 \mathrm{~m}^{2} \mathrm{~g}^{-1}, 0.012 \mathrm{~cm}^{3} \mathrm{~g}^{-1}$, and $51 \AA$, respectively.

This result indicates that there are huge physical changes of the C20 (as the host) before the encapsulation of the PCM for the formation of the SSPCM-C20, after the PCM (as the guest) was encapsulated into the pores of AC. The encapsulation caused a reduction of the BET surface area and porosity, as well as the transformation from a microporous material to a nonporous material, as indicated by the adsorption-desorption isotherm from Type I to Type III. These changes happened because the pores of $\mathrm{C} 20$ were fully occupied by the n-octadecane after the encapsulation process. This result clearly proves that the SSPCM-C20 nano-composite was successfully fabricated by the impregnation of n-octadecane into the pores of $\mathrm{C} 20$ frameworks.

The size of a single n-octadecane molecule was estimated using the Pymol software. The 3D molecular structure of n-octadecane had a maximum energy of $44.4874 \mathrm{KJ} \mathrm{mol}^{-1}$ with a size of $(20.7 \times 1.8 \times 1.8) \AA$ A. This size proves that $n$-octadecane can be impregnated into the pores of the activated carbon that dominate with a $12.85 \AA$ pore diameter. 


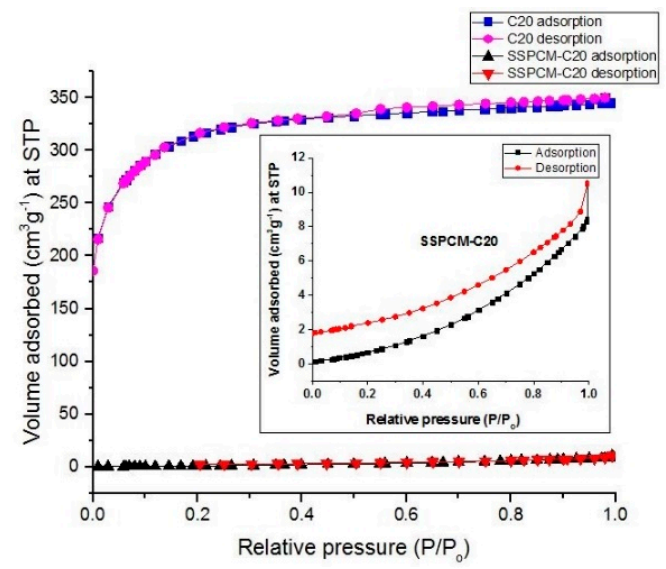

(a)

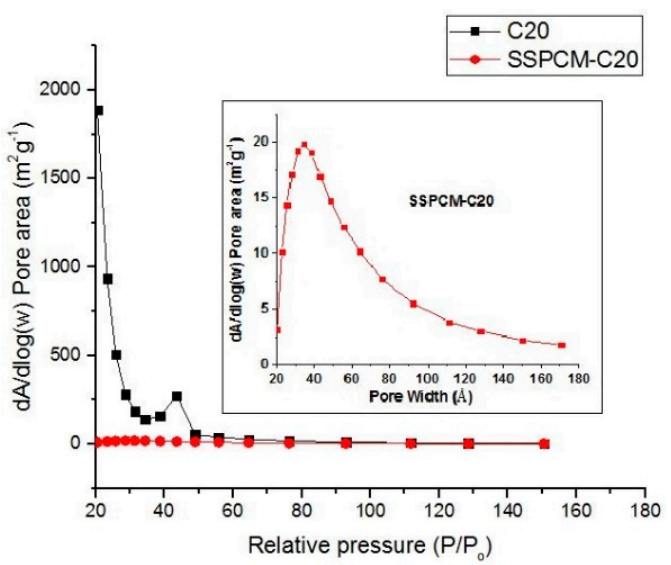

(b)

Figure 3. The (a) adsorption-desorption isotherm and (b) pore distribution of the activated carbon (C20) and its Shape-stabilized phase change material (SSPCM-C20). The insets show the expanded y-axis.

\subsection{Fourier-Transform Infrared Spectroscopy}

The chemical characterization of the C20, n-octadecane, and SSPCM-C20 was carried out using the FTIR spectroscopy as shown in Figure 4. The main absorption band of C20 is observed in the region of 3650-2500 $\mathrm{cm}^{-1}$ due to the $\mathrm{O}-\mathrm{H}$ stretching presumably due to $\mathrm{H}_{3} \mathrm{PO}_{4}$ treatment used and adsorbed moisture. The bands at 1635 and $1537 \mathrm{~cm}^{-1}$ correspond to the $\mathrm{C}=\mathrm{C}$ stretching of the aromatic ring carbon of the polycyclic aromatic hydrocarbons that forms the basic structural unit of activated carbons. The absorption bands at $1463 \mathrm{~cm}^{-1}$ and $1385 \mathrm{~cm}^{-1}$ are due to the $\mathrm{CH}_{2}$ bending vibrations.

The FTIR spectra of n-octadecane exhibit C-H stretching in the region of $2975-2850 \mathrm{~cm}^{-1}$ corresponding to the main absorption band for the n-octadecane. The absorption band at $1470 \mathrm{~cm}^{-1}$ is due to the $\mathrm{CH}_{2}$ bending vibration in n-octadecane. The FTIR spectrum of the SSPCM-C20 nano-composite shows the combination of $\mathrm{O}-\mathrm{H}$ and $\mathrm{C}-\mathrm{H}$ stretching that corresponds to the absorption band in C20 and the n-octadecane. Based on the FTIR spectra, no chemical interaction between the n-octadecane and C20 can be observed. The possible interaction is due to capillary and surface tension forces between the $\mathrm{AC}$ and the paraffin, where the forces prevent the liquid leakage of the melted n-octadecane.

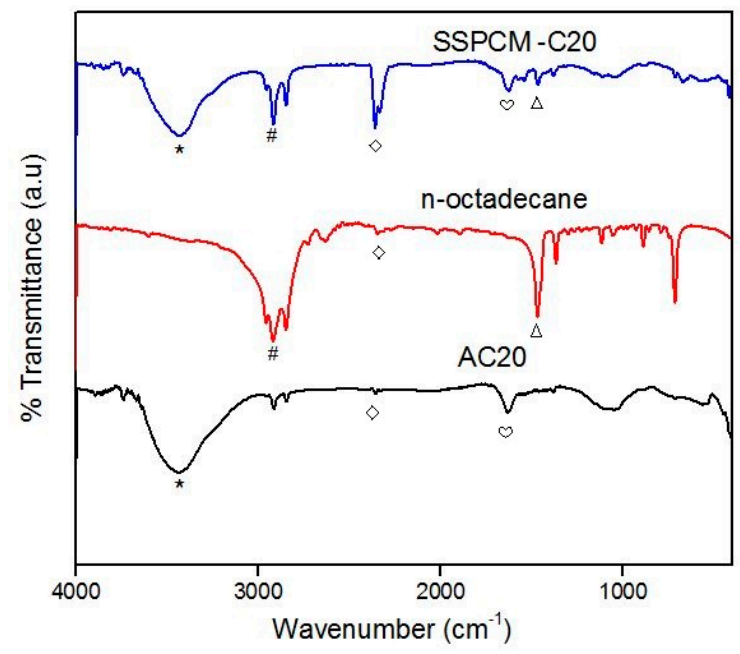

Figure 4. The FTIR spectra of C20, n-octadecane, and SSPCM-C20 (the symbols on the FTIR spectra are

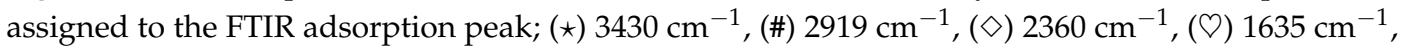
( $\Delta) 1470 \mathrm{~cm}^{-1}$. 


\subsection{X-ray Diffraction}

The XRD patterns of C20, n-octadecane, and the SSPCM-C20 nano-composite are displayed in Figure 5. The C20 was analyzed at room temperature while the n-octadecane and SSPCM-C20 were analyzed at $27 \pm 5{ }^{\circ} \mathrm{C}$ in order to maintain the solid phase of PCM while we acquired the data. The result shows that there were no XRD peaks for the C20, as the material used in this study is of an amorphous type. In contrast, an XRD pattern for the SSPCM-C20 nano-composite is observed at $2 \theta=19^{\circ}, 23^{\circ}$, and $25^{\circ}$, which belongs to n-octadecane due to its crystallization in the solid phase condition. It can be seen that the XRD pattern of the SSPCM-C20 resembles that of the C20 and the n-octadecane. This infers that the n-octadecane was successfully impregnated into the pores of C20.

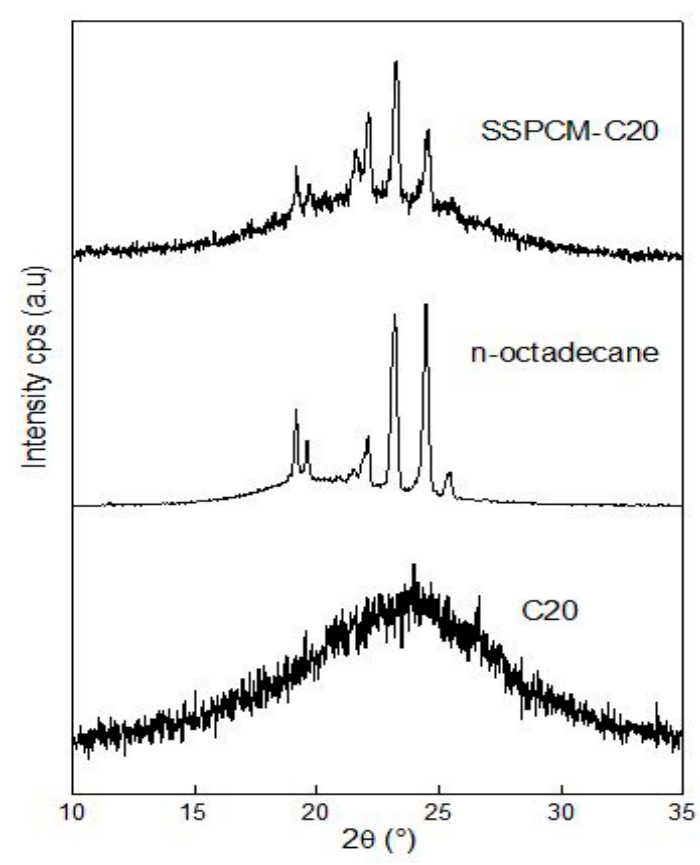

Figure 5. The X-Ray Diffraction patterns of C20, n-octadecane, and SSPCM-C20.

\subsection{Thermal Properties}

The TGA/DTG analysis was used to study the thermal stability of the SSPCM-C20. For the TES application, the thermal stability of the material is very important. Figure $6 a-c$ show the TGA/DTG thermograms of C20, n-octadecane, and SSPCM-C20. C20 shows no thermal decomposition of the sample below $512{ }^{\circ} \mathrm{C}$, however, a decomposition was observed from this temperature up to $861^{\circ} \mathrm{C}$ due to further pyrolysis. This is because the carbonization of $\mathrm{C} 20$ was done at only $500{ }^{\circ} \mathrm{C}$. This result indicates that the AC produced is thermally stable up to $513^{\circ} \mathrm{C}$. The $\mathrm{C} 20$ is thermally stable until $500{ }^{\circ} \mathrm{C}$ and able to be used as a supporting material for PCM. In contrast, the n-octadecane shows a weight loss between $94.00-253.7^{\circ} \mathrm{C}$, which is due to the evaporation of n-octadecane. The SSPCM-C20 nano-composite exhibits a similar thermal stability to that of C20. In general, the weight loss of the SSPCM-C20 nano-composite agrees well with the one obtained from the DSC result with an encapsulation efficiency of $32 \%$.

Table 1 shows the percentage weight loss of C20, n-octadecane, and SSPCM-C20 upon being subjected to thermal treatment from room temperature to $1000{ }^{\circ} \mathrm{C}$. The result shows that C20 exhibits a $25.08 \%$ weight loss; $8.49 \%$ from the evaporation of water and $16.59 \%$ from the decomposition of C20 at temperatures higher than $500{ }^{\circ} \mathrm{C}$. It was found that $100 \%$ of pure n-octadecane was evaporated, while SSPCM-C20 shows a total weight loss of 51.16\%, with 3.22\% due to the evaporation of moisture, $31.96 \%$ due to the evaporation of n-octadecane, and $15.98 \%$ due to the decomposition of C20 at temperatures higher than $518{ }^{\circ} \mathrm{C}$ in the SSPCM-C20. 


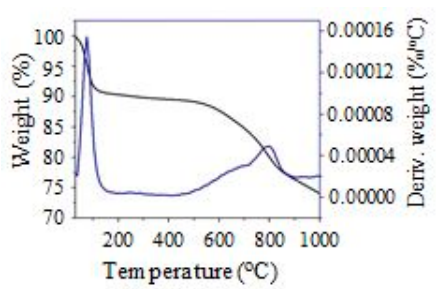

(a)

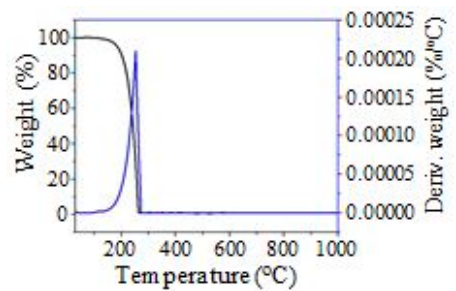

(b)

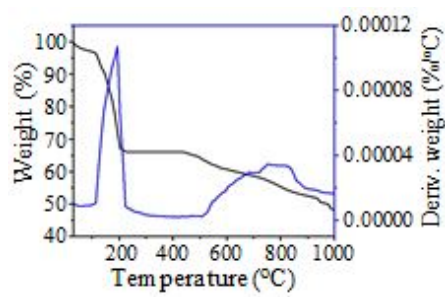

(c)

Figure 6. The Thermogravimetric analysis thermograms of (a) C20, (b) n-octadecane and (c) SSPCM-C20.

Table 1. The thermal properties of n-octadecane, C20, and SSPCM-C20 derived from Thermogravimetric analysis thermograms.

\begin{tabular}{|c|c|c|c|c|c|}
\hline Sample Name & $\mathrm{T}_{1}-\mathrm{T}_{2}\left({ }^{\circ} \mathrm{C}\right)$ & $\mathrm{T}_{\mathrm{m}}\left({ }^{\circ} \mathrm{C}\right)$ & $\Delta_{\mathrm{m}}(\mathrm{mg})$ & Weight Loss (\%) & Total Weight Loss $(\%)$ \\
\hline \multirow{2}{*}{$\mathrm{C} 20$} & 34-109 & 75 & 0.89 & 8.49 & \multirow{2}{*}{25.08} \\
\hline & $513-861$ & 796 & 1.74 & 16.59 & \\
\hline n-octadecane & $94-273$ & 261 & 10.69 & 100.00 & 100.00 \\
\hline \multirow{3}{*}{ SSPCM-C20 } & $47-87$ & 58 & 0.34 & 3.22 & \multirow{3}{*}{51.16} \\
\hline & $115-263$ & 193 & 3.38 & 31.96 & \\
\hline & $518-853$ & 761 & 1.69 & 15.98 & \\
\hline
\end{tabular}

\subsection{Differential Scanning Calorimetry}

The melting and freezing activity of the PCM was characterized using the differential scanning calorimeter (DSC) method. Figure 7 shows the DSC curves of the C20, n-octadecane, and SSPCM-C20. The DSC thermogram shows no activity of melting and freezing for C20 due to the absence of n-octadecane. In contrast, the DSC thermograms for n-octadecane and SSPCM-C20 shows peaks of solid-liquid melting and liquid-solid freezing which indicate that heat was absorbed and released for n-octadecane and SSPCM-C20. The pure n-octadecane shows sharper peaks compared to SSPCM-C20. This is because the AC that acted as a framework for the n-octadecane in SSPCM-C20 exhibits a higher adsorption capability compared to n-octadecane, which increases the capillary effect and surface tension forces between the n-octadecane and the porous network of the AC and hinders the molecular motion of n-octadecane during the melting and freezing processes.

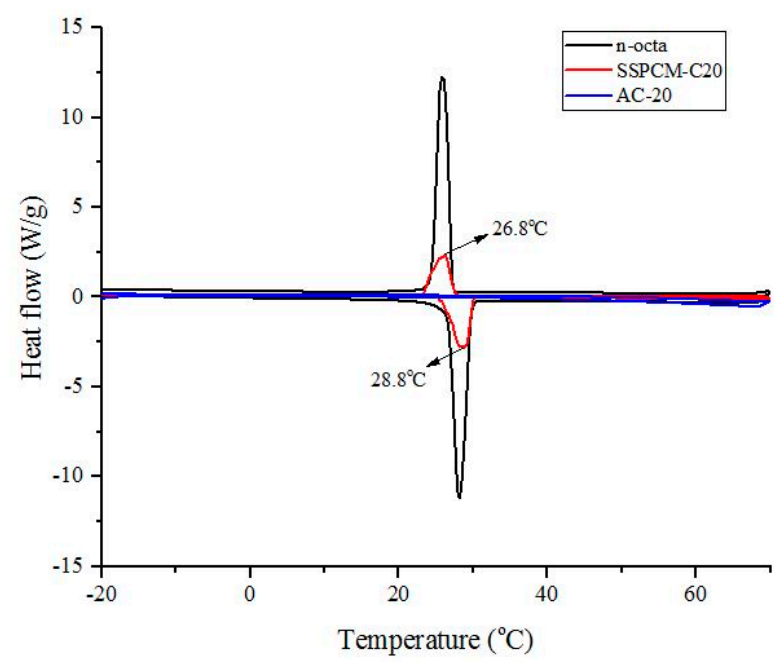

Figure 7. The Differential scanning calorimeter thermograms of C20, n-octadecane and SSPCM-C20. 
The supercooling effect of the nano-composite was calculated by the difference between the melting point and the freezing temperature of the sample. The SSPCM nano-composite shows the melting and freezing temperatures of $28.8^{\circ} \mathrm{C}$ and $26.8^{\circ} \mathrm{C}$, respectively, corresponding to the latent heat values of $-87.42 \mathrm{Jg}^{-1}$ and $84.31 \mathrm{Jg}^{-1}$, respectively, indicating a very low supercooling effect. It also shows that pure n-octadecane and SSPCM-C20 have similar thermal properties, which indicates that there is no chemical reaction between them. This finding infers that n-octadecane was successfully impregnated into the pores of C20.

\subsection{Surface Morphology}

Figure 8 shows the FESEM images of the PKS, C20, and SSPCM-C20 which show different morphologies of the samples. Figure 8a shows the morphology of the PKS, which was used as the precursor for the preparation of activated carbon. The resulting activated carbon prepared from PKS, activated using $\mathrm{H}_{3} \mathrm{PO}_{4}$, and carbonized at 500 for $2 \mathrm{~h}$ shows a well-developed porous structure with quite a similar shape and size with various pore sizes as shown in Figure $8 \mathrm{~b}$. As a result of the encapsulation of n-octadecane into the pores of activated carbon, n-octadecane was absorbed into the porous networks of C20 and completely dispersed and occupied homogeneously into the pores, resulting in the absence of pores.

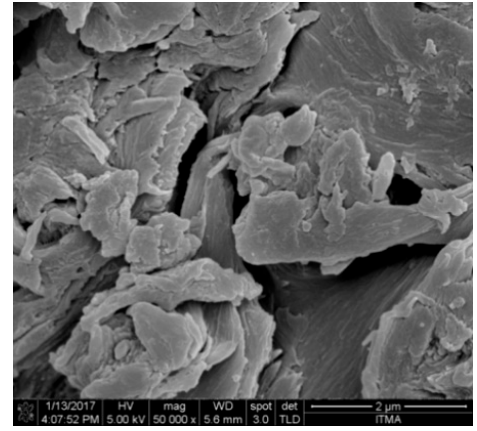

(a)

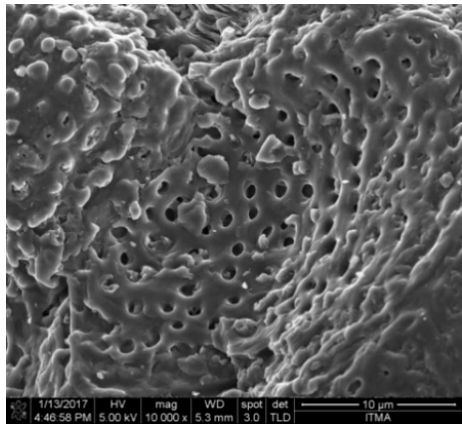

(b)

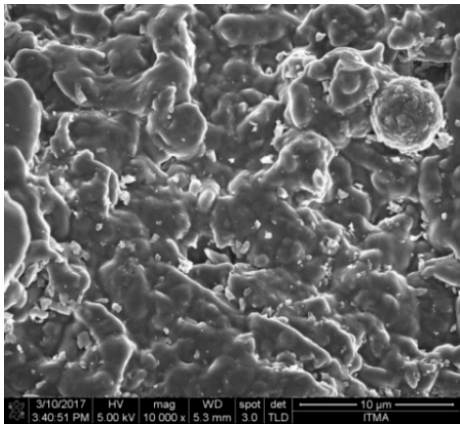

(c)

Figure 8. The Field Emission Scanning Electron Microscopy surface morphology images of (a) PKS (50000 $\times$ magnification), (b) C20 and (c) SSPCM-C20 (viewed under 10,000 $\times$ magnification).

The n-octadecane was uniformly distributed into the pores of AC due to the capillary effect and surface tension forces between n-octadecane and the pores of AC. In addition, the surface adsorption of n-octadecane on C20 cannot be ruled out. The porous structure of the C20 provides a mechanical strength which prevented the escape of the melted n-octadecane.

\subsection{Leakage Study}

The purpose of this test is to see the ability of the C20 to hold n-octadecane at temperatures over the melting temperature of n-octadecane. The filter paper shows no leakage, i.e., no oily marks on the paper and the sample is still in a dry condition after being exposed to $30^{\circ} \mathrm{C}$ for $8 \mathrm{~h}$. Table 2 summarizes the weight and latent heat of the SSPCM-C20 nano-composites before and after the leakage study. The weight after it was exposed to $80^{\circ} \mathrm{C}$ for 3 days shows a reduction of $0.0409 \mathrm{~g}$ from $1 \mathrm{~g}$ of SSPCM-C20 used in this study. This insignificant difference of weight indicates that no leakage happened during the study. The latent heat of SSPCM-C20 before and after the leakage study also shows no significant difference. This is because the wall of the pores and n-octadecane provide strong adhesive forces that are built from a strong covalent bond that prevents any seepage of liquefied n-octadecane. Table 2 shows that the loading of n-octadecane is 34\%, which is equivalent to the PCM that managed to be loaded into the pores of the activated carbon. This loading percentage of n-octadecane is similar to the weight loss percentage of n-octadecane in the TGA analysis. This result reconfirmed that the 
n-octadecane successfully penetrated and was encapsulated into the pores structure of PKSAC with a $34 \%$ loading value.

Table 2. The weight and latent heat of the SSPCM-C20 nano-composites before and after the leakage study.

\begin{tabular}{|c|c|c|c|c|c|c|c|c|}
\hline \multirow{2}{*}{ Sample } & \multirow{2}{*}{$\begin{array}{c}\text { BET Surface } \\
\text { Area }\left(\mathrm{m}^{2} \mathrm{~g}^{-1}\right)\end{array}$} & \multirow{2}{*}{$\begin{array}{l}\text { Pore Volume } \\
\qquad\left(\mathrm{cm}^{3} \mathrm{~g}^{-1}\right)\end{array}$} & \multirow{2}{*}{$\begin{array}{l}\text { Pore Diameter } \\
\text { ( } \AA \text { ) }\end{array}$} & \multirow{2}{*}{$\begin{array}{l}\text { PCM Loading } \\
(\%)\end{array}$} & \multicolumn{2}{|c|}{ Latent Heat Before $\left(\mathrm{J} \mathrm{g}^{-1}\right)$} & \multicolumn{2}{|c|}{ Latent Heat After $\left(\mathrm{J} \mathrm{g}^{-1}\right)$} \\
\hline & & & & & $\Delta \mathrm{H}_{\mathrm{m}}{ }^{\mathrm{a}}\left(\mathrm{J} \mathrm{g}^{-1}\right)$ & $\Delta H_{c}{ }^{b}\left(\mathrm{~J} \mathrm{~g}^{-1}\right)$ & $\Delta H_{m}{ }^{c}\left(J^{-1}\right)$ & $\Delta \mathrm{H}_{\mathrm{c}}{ }^{\mathrm{d}}\left(\mathrm{J} \mathrm{g}^{-1}\right)$ \\
\hline SSPCM-20 & 2 & 0.012 & 51 & 33.62 & -87.42 & 84.31 & -85.31 & 84.13 \\
\hline
\end{tabular}

${ }^{a}$ enthalpy on the DSC melting curve before the leaching test; ${ }^{b}$ enthalpy on the DSC freezing curve before the leaching test; ${ }^{c}$ enthalpy on the DSC melting curve after the leaching test; and ${ }^{\mathrm{d}}$ enthalpy on the DSC freezing curve after the leaching test.

\subsection{Thermal Cycling Test}

The thermal cycling test was performed to investigate the physical and chemical stability of the SSPCM-C20 nano-composite when it was exposed to temperature changes. The repeated cycles of the temperature change the thermal behaviour of the material. Changes in the thermal behaviour of the nano-composite will affect its application as a TES. The number of cycles that the sample was able to withstand imitates the life-spend of the materials. For example, if there are no changes in the chemical or thermal properties of the nano-composite after 1000 cycles, the composite can be used in the building material to reduce and maintain the internal temperature for a minimum of 3 years. The higher cycle the SSPCM-C20 nano-composite can withstand, the better its application as a TES for building applications.

Figure 9 shows the DSC thermograms (a) and FTIR spectra (b) of SSPCM-C20 after 100-500 cycles. The DSC thermograms show peaks of solid-liquid melting and liquid-solid freezing for 100-500 cycles. After 300 cycles, the melting and freezing peaks of the nano-composite were reduced, compared to 100 cycles. No melting and freezing activity for SSPCM-C20 was observed after 500 cycles. The peak keeps reducing until it disappeared at 500 cycles, which indicated that there are changes in the thermal properties of the SSPCM-C20 nano-composite. The FTIR spectra of the SSPCM-C20 nano-composite after 100, 300, and 500 cycles show similar FTIR features, indicating a similar chemical structure and that no chemical reaction between the C-20 and n-octadecane can be clearly observed.

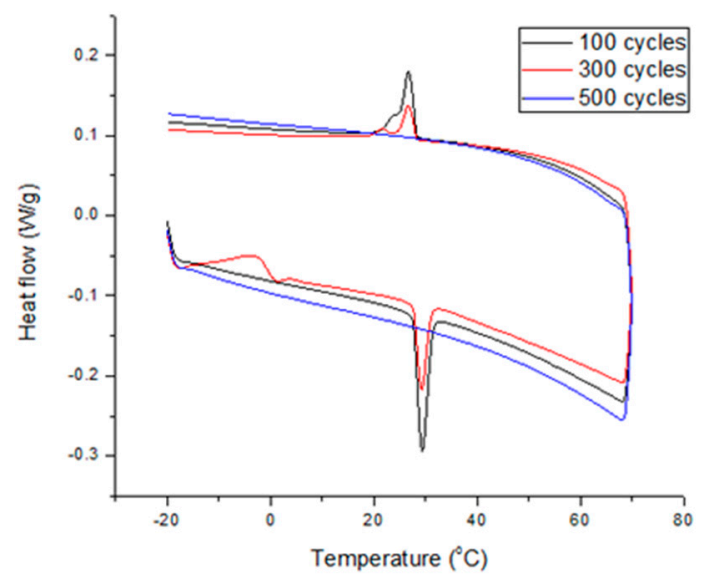

(a)

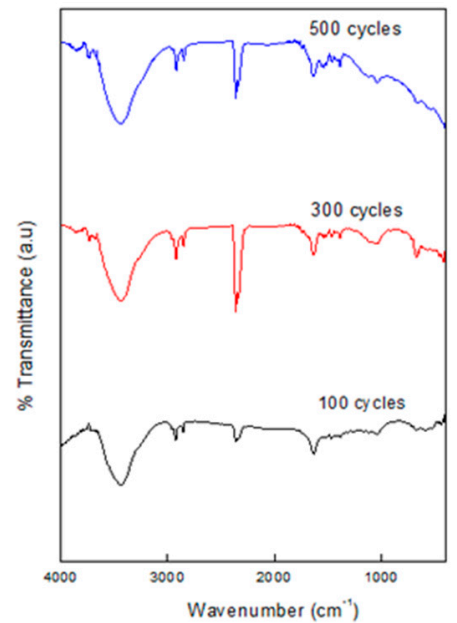

(b)

Figure 9. The (a) DSC thermograms and (b) FTIR spectra of SSPCM-C20 after 500 cycles of thermal cycling test. 


\section{Conclusions}

The activated carbon prepared using PKS (PKSAC) as the precursor shows a good graphitic characteristic at the following optimum conditions: $20 \% \mathrm{H}_{3} \mathrm{PO}_{4}(w / w)$ at $2 \mathrm{~h}$ holding time and $500{ }^{\circ} \mathrm{C}$ carbonization temperature. The nitrogen adsorption-desorption isotherm shows that the resulting PKSAC is micropore-rich as indicated by the Type I adsorption-desorption isotherm with the highest BET surface area of $1169 \mathrm{~m}^{2} \mathrm{~g}^{-1}$ and $\mathrm{I}_{\mathrm{G}} / \mathrm{I}_{\mathrm{D}}$ ratio of 1.305 . When the resulting PKSAC was used as the frameworks for the encapsulation of the PCM material, n-octadecane, for the formation of a shape-stabilised PCM, the nitrogen adsorption-desorption isotherm changed to a non-porous material of Type III with the BET surface area reduced to only $2 \mathrm{~m}^{2} \mathrm{~g}^{-1}$. The change of the type of isotherm and the reduction of the BET surface area proves that the pores of the AC were fully occupied by the n-octadecane after the impregnation processes. The FESEM studies also show that the pores of the activated carbon were fully occupied by the PCM materials.

The interaction between the wall of the pores and the n-octadecane due to the strong covalent bond provides strong adhesive forces that prevent any seepage of the liquefied n-octadecane. The SSPCM-C20 is chemically and thermally stable, capable of standing up to 500 cycles. This result shows that the SSPCM-C20 nano-composite is thermally and chemically reliable to be used as a TES application. Due to the fact that the PKS was obtained from bio-wastes of the palm oil industry, the reproducibility is expected to be low. It is difficult to repeat and have exactly the same result for the experiment due to several aspects. The raw material used, processing methods and productions conditions will directly affect the physicochemical properties of the AC [22]. However, this experiment could be improved using other raw materials because the properties of the resulting AC produced are very much dependent on the precursor used. In addition, the further optimization on the preparation of AC framework can be accomplished using other precursors, activating agents, and different carbonization temperatures and holding times, so that a higher loading percentage of PCM and better thermal energy storage materials can be obtained.

Supplementary Materials: The following are available online at http:/ /www.mdpi.com/2079-4991/8/9/689/s1, Figure S1: Raman spectra of PKSAC, Figure S2: Adsorption-desorption isotherms.

Author Contributions: A.F.N. conducted the preparation and characterization of Activated carbon and SSPCM and wrote the manuscript. M.Z.H., Z.Z. and T.K. supervised the project and edited the manuscript. All authors discussed the results and commented on the manuscript at all stages.

Acknowledgments: We would like to thank Universiti Putra Malaysia and the Ministry of Higher Education of Malaysia (UPM-MOHE) for funding this project under NANOMITE grant, vote No. 5526300 and 9443100.

Conflicts of Interest: The authors declare no conflict of interest.

\section{References}

1. Herawan, S.G.; Hadi, M.S.; Ayob, M.R.; Putra, A. Characterization of activated carbons from oil palm shell by $\mathrm{CO}_{2}$ activation with no holding carbonization temperature. Sci. World J. 2013, 624865.

2. Foo, K.Y.; Hameed, B.H. Dynamic adsorption behaviour of methylene blue onto oil palm shell granular activated carbon prepared by microwave heating. Chem. Eng. J. 2012, 203, 81-87. [CrossRef]

3. Alam, M.Z.; Muyibi, S.A.; Mansor, M.F.; Wahid, R. Activated carbons derived from oil palm empty-fruit bunches: Application to environmental problems. J. Environ. Sci. 2007, 19, 103-108. [CrossRef]

4. Foo, K.Y.; Hameed, B.H. Porous structure and adsorptive properties of pineapple peel based activated carbons prepared via microwave assisted $\mathrm{KOH}$ and $\mathrm{K}_{2} \mathrm{CO}_{3}$ activation. Microporous Mesoporous Mater. 2012, 148, 191-195. [CrossRef]

5. Rincón, S.L.; Gómez, A. Comparative behaviour of agricultural biomass residues during thermochemical processing. Glob. Nest J. 2012, 14, 111-117.

6. Didaskalou, C.; Buyuktiryaki, S.; Kecili, R.; Fonte, C.P.; Szekely, G. Valorization of agricultural waste with an adsorption/nanofiltration hybrid process: from materials to sustainable process design. Green Chem. 2017, 19, 3116-3125. [CrossRef] 
7. Nik, W.B.W.; Rahman, M.M.; Yusof, A.M.; Ani, F.N.; Adnan, C.M.C. Production of activated carbon from palm oil shell waste and its adsorption characteristics. In Proceedings of the 1st International Conference on Natural Resources Engineering \& Technology, Putrajaya, Malaysia, 24-25 July 2006; pp. 646-654.

8. Hesas, R.H.; Arami-Niya, A.; Daud, W.M.A.W.; Sahu, J.N. Microwave-assisted production of activated carbons from oil palm shell in the presence of $\mathrm{CO}_{2}$ or $\mathrm{N}_{2}$ for $\mathrm{CO}_{2}$ adsorption. J. Ind. Eng. Chem. 2015, 24, 196-205. [CrossRef]

9. Huang, C.P. The removal of chromium (VI) from diluted aqueous solution by activated carbon. Water Res. 1977, 11, 673-679. [CrossRef]

10. Gonzalez-Serrano, E.; Cordero, T.; Rodriguez-Mirasol, J.; Cotoruelo, L.; Rodriguez, J.J. Removal of water pollutants with activated carbons prepared from $\mathrm{H}_{3} \mathrm{PO}_{4}$ activation of lignin from kraftblack liquors. Water Res. 2004, 13, 3043-3050. [CrossRef] [PubMed]

11. Hesas, R.H.; Arami-Niya, A.; Daud, W.M.A.W.; Sahu, J.N. Comparison of oil palm shell-based activated carbons produced by microwave and conventional heating methods using zinc chloride activation. J. Anal. Appl. Pyrolysis 2013, 104, 176-184. [CrossRef]

12. Lillo-Ródenas, M.A.; Cazorla-Amorós, D.; Linares-Solano, A. Understanding chemical reactions between carbons and $\mathrm{NaOH}$ and $\mathrm{KOH}$ : An insight into the chemical activation mechanism. Carbon 2003, 41, 267-275. [CrossRef]

13. Hussein, M.Z.B.; Rahman, M.B.B.A.; Yahaya, A.H.J.; Hin, T.-Y.Y.; Ahmad, N. Oil palm trunk as a raw material for activated carbon production. J. Porous Mater. 2001, 8, 327-334. [CrossRef]

14. Ahmad, A.L.; Ismail, S.; Bhatia, S. Water recycling from palm oil mill effluent (POME) using membrane technology. Desalination 2003, 157, 87-95. [CrossRef]

15. Fodi, T.; Didaskalou, C.; Kupai, J.; Balogh, G.T.; Huszthy, P.; Szekely, G. Nanofiltration-enabled in situ solvent and reagent recycle for sustainable continuous-flow synthesis. ChemSusChem 2017, 10, 3435-3444. [CrossRef] [PubMed]

16. Schaepertoens, M.; Didaskalou, C.; Kim, J.F.; Livingston, A.G.; Szekely, G. Solvent recycle with imperfect membranes: A semi-continuous workaround for diafiltration. J. Membr. Sci. 2016, 514, 646-658. [CrossRef]

17. Nomura, T.; Okinaka, N.; Akiyama, T. Impregnation of porous material with phase change material for thermal energy storage. Mater. Chem. Phys. 2009, 115, 846-850. [CrossRef]

18. Hasnain, S.M. Review on sustainable thermal energy storage technologies, Part I: heat storage materials and techniques. Energy Convers. Manag. 1998, 39, 1127-1138. [CrossRef]

19. Zhang, Z.; Zhang, N.; Peng, J.; Fang, X.; Gao, X.; Fang, Y. Preparation and thermal energy storage properties of paraffin/expanded graphite composite phase change material. Appl. Energy 2012, 91, 426-431. [CrossRef]

20. Khadiran, T.; Hussein, M.Z.; Zainal, Z.; Rusli, R. Activated carbon derived from peat soil as a framework for the preparation of shape-stabilized phase change material. Energy 2015, 82, 468-478. [CrossRef]

21. Zhang, X.; Yan, Q.; Leng, W.; Li, J.; Zhang, J.; Cai, Z.; Hassan, E.B. Carbon nanostructure of kraft lignin thermally treated at 500 to $1000{ }^{\circ} \mathrm{C}$. Materials 2017, 10, 975. [CrossRef] [PubMed]

22. Lee, T.; Zubir, Z.A.; Jamil, F.M.; Matsumoto, A.; Yeoh, F.Y. Combustion and pyrolysis of activated carbon fibre from oil palm empty fruit bunch fibre assisted through chemical activation with acid treatment. J. Anal. Appl. Pyrolysis 2014, 110, 408-418. [CrossRef]

(C) 2018 by the authors. Licensee MDPI, Basel, Switzerland. This article is an open access article distributed under the terms and conditions of the Creative Commons Attribution (CC BY) license (http:/ / creativecommons.org/licenses/by/4.0/). 